\title{
Resultados do Dia Nacional de Prevenção ao Câncer de Pele do ano de 2013 na cidade de Rio Grande, Rio Grande do Sul, Brasil
}

\author{
Danielski, T.P.; Lorenzi, C.; Miranda, B.S.; Conejo, V.S.; Rodrigues, O.;
}

Apresentador: Tatiana Peres Danielski

\section{Resumo}

Introdução: O câncer de pele não melanoma é um problema de saúde pública, devido ser o câncer de maior incidência no Brasil. Assim, a Sociedade Brasileira de Dermatologia celebra há 14 anos o Dia Nacional de Combate ao Câncer de Pele, visando sua prevenção e diagnóstico precoce. Perante esse quadro, o presente estudo tem como objetivo apresentar os resultados dos dados coletados na campanha realizada na cidade de Rio Grande - RS em 2013. São apresentados dados da frequência das lesões, perfil da população encaminhada, diagnóstico anatomopatológico e padrão de exposição solar. O objetivo desse trabalho é a análise os dados coletados, para elaboração, no futuro, de medidas cada vez mais efetivas para prevenção do câncer de pele para a sociedade do sul do Brasil. Métodos: O Dia Nacional de Combate ao Câncer de Pele ocorre no último sábado do mês de novembro. Os atendimentos são realizados em ambulatórios, sendo os pacientes atendidos por dermatologistas. Aqueles apresentando suspeita de câncer da pele são encaminhados para cirurgia. A lesão excisada é enviada para exame anatomopatológico. Os pacientes com lesão suspeita respondem um questionário referente ao perfil de exposição solar, resultando numa análise quantitativa dos dados. O presente estudo segue as normas de pesquisa com pacientes. Resultados: Das 68 lesões com diagnóstico, aproximadamente $56,76 \%$ tiveram o diagnóstico de malignidade, sendo 28 casos de carcinoma basocelular, 7 casos de carcinoma escamocelular e nenhum melanoma. O local de maior ocorrência das lesões foi em face, com 59,01 dos casos. A média de idade dos entrevistados foi de 61,6 anos. Dos entrevistados $93.06 \%$ eram alfabetizados. Com relação ao uso atual de proteção solar, $51,39 \%$ fazia uso de algum tipo de proteção. Quanto a lesões prévias, $51,39 \%$ tiveram resposta positiva. A respeito do padrão de exposição solar, 13,89\%\% afirmam expor-se antes das 10 da manhã, $88,89 \%$ por longos períodos durante a infância, $55,56 \%$ já tiveram queimadura solar, $54,17 \%$ se expõem ao sol no trabalho. Ainda, 45,83\% não sabem o que significa índice ultravioleta e $98,61 \%$ consideram a sua divulgação por meios de comunicação importante. Conclusão: Com o diagnóstico das lesões suspeitas, os fatores de risco e as exposições habituais é possível criar um padrão epidemiológico e elaborar planos de prevenção de acordo com a exposição a fatores de risco dos pacientes. Assim, conhecer o perfil da população é a melhor forma de promover e reinstaurar a saúde.

\section{Referência:}

Danielski, T.P.; Lorenzi, C.; Miranda, B.S.; Conejo, V.S.; Rodrigues, O.;. Resultados do Dia Nacional de Prevenção ao Câncer de Pele do ano de 2013 na cidade de Rio Grande, Rio Grande do Sul, Brasil. In: Il Congresso Brasileiro de Medicina Hospitalar - II CBMH [= Blucher Medical Proceedings, vol.1, num.5] São Paulo: Editora Blucher, 2014. p.68 DOI 10.5151/medpro-II-cbmh-065 